\title{
The influence of physicochemical properties of water on plasma indices in brook trout (Salvelinus fontinalis, Mitchill) reared under conditions of intensive aquaculture
}

\author{
Radovan Kopp ${ }^{1,2}$, Štěpán Lang ${ }^{1}$, Tomáš Brabec ${ }^{1}$, Jan Mareš ${ }^{1}$ \\ ${ }^{1}$ Mendel University in Brno, Faculty of Agronomy, Department of Fishery and Hydrobiology, \\ Brno, Czech Republic \\ ${ }^{2}$ Institute of Botany AS CR (Centre for Cyanobacteria and Their Toxins), Brno, Czech Republic
}

Received January 30, 2013

Accepted September 26, 2013

\begin{abstract}
The breeding of salmonids in intensive aquaculture has increasing importance in terms of high quality fish crude. The aim of our study was to figure out if the physicochemical properties of water can influence the physiological condition of fish organism. Blood samples were taken from the heart of 86 healthy, randomly selected brook trout (Salvelinus fontinalis) with the standard length of $242.3 \pm 10.8 \mathrm{~mm}$ and body mass of $261.10 \pm 29.81 \mathrm{~g}$. Sampling was done on three trout farms in the Czech Republic in the period between autumn 2009 and summer 2011. Blood plasma was analysed for the presence of 23 plasma indices by automated blood plasma analyser. Chemical properties of water had a significant $(P<0.001)$ influence on the content of alkaline phosphatase, cholinesterase, amylase, lipase, total protein, albumin, $\mathrm{P}, \mathrm{Ca}$ and $\mathrm{K}$ in plasma of the brook trout. Plasma indices were influenced especially by water temperature, oxygen saturation, and the content of ammonium ions, total nitrogen, iron and conductivity. This is the first complex study focusing on the influence of chemical and physical composition of water on blood plasma indices of brook trout.
\end{abstract}

\section{Fish, salmonids, biochemical variables, chemical properties, fish farming}

Development of intensive aquaculture requires the examination of the state of health of fish including also approaches that involve clinical biochemical diagnostics. Such approaches serve to identify the onset of any organ failure caused by the use of wrong feeds and to draw attention to changes in the abiotic factors of the environment and to any complications due to infection or parasitic invasion. To identify as many pathological deviations as possible, it is advisable to use more than one test reflecting the basic metabolic functions ( ̌̌ ehulka and Minařík 2008). Fish blood plasma chemistry is a promising area in fish biology and clinical pathology although it requires further research particularly in assessment of normal range. More studies need to be performed with a focus on the clinical analysis of blood as an indicator of the physiological state of the brook trout in aquaculture (Diouf et al. 2000; Řehulka and Minařík 2007). Moreover, apart from the inevitable differences in, e.g. methodology, fish size and strains, season and physiological condition, it is often difficult to find an exhaustive set of blood chemistry which estimates for trout in a single study (Manera and Britti 2006).

The aim of the present study was to assess plasma indices in brook trout (Salvelinus fontinalis) from aquaculture system. The basic characteristics of fish organism physiological condition through selected biochemical indices of the blood plasma were examined.

\section{Materials and Methods}

Experimental fish and sampling

Clinically healthy immature brook trout (Salvelinus fontinalis) were provided from three fish farms from 19 November 2009 to 3 August 2011. Samples from the fish farm Pravíkov were collected in November $\left(19^{\text {th }}, \mathrm{n}=10\right)$, March $\left(4^{\text {th }}, \mathrm{n}=10\right)$, June $\left(15^{\text {th }}, \mathrm{n}=6\right)$, July $\left(19^{\text {th }}, \mathrm{n}=18\right)$ and August $\left(3^{\text {rd }}, \mathrm{n}=12\right)$, samples

Address for correspondence:

Radovan Kopp, Ph.D. Associate Professor

Department of Fishery and Hydrobiology

Mendel University

Zemědělská 1, 61300 Brno, Czech Republic

Phone: +420 545133268

Fax: +420545133267

E-mail: kopp@mendelu.cz

http://actavet.vfu.cz/ 
from the fish farm Skalní mlýn were collected in August $\left(4^{\text {th }}, \mathrm{n}=10\right)$ and March $\left(11^{\text {th }}, \mathrm{n}=10\right)$ and samples from the fish farm Litomyšl were collected in March $\left(25^{\text {th }}, \mathrm{n}=10\right)$. There are two rearing systems with different environment conditions in the Pravíkov fish farm: old recirculation system (ORS) with water inflowing from the fishpond, and new recirculation system of Danish type (NRS) with water inflowing from the stream.

The fish were fed the same commercial diets containing $40-43 \%$ crude protein, $23-28 \%$ crude fat, $12-20 \%$ carbohydrates, $6-8.3 \%$ ash, $1-3.8 \%$ crude fibre, $1.3 \% \mathrm{Ca}$ and $0.9 \% \mathrm{P}$. The fish were fasted $24 \mathrm{~h}$ prior to blood sampling. For every fish $(\mathrm{n}=86)$ randomly selected, the following biometrical data were measured or calculated $($ mean \pm SD): total length $(270.0 \pm 9.3 \mathrm{~mm})$, standard length $(242.3 \pm 10.1 \mathrm{~mm})$, body mass $(261.1 \pm 29.8 \mathrm{~g})$, liver mass $(4.57 \pm 0.83)$, hepatosomatic index $(1.95 \pm 0.32)$ and Fulton's condition factor $(1.75 \pm 0.12)$ (Fulton 1904). The experiment followed experimental project no. 13321/2009-30.

Immediately after catching the fish from the fish farm, 110 blood samples were collected. Fish blood was taken by cardiac puncture using heparinised syringes. Heparin at the concentration of $50 \mathrm{IU}$ per ml was used for blood stabilization. In total, 24 inadequate and haemolytic plasma samples were removed from sample collection. The blood was centrifuged at $400 \mathrm{~g}$ for $15 \mathrm{~min}$ at $4{ }^{\circ} \mathrm{C}$. Plasma supernatant was stored at $-80{ }^{\circ} \mathrm{C}$ until the day of analyses. Biochemical analyses were performed by the ADVIA 1650 automatic analyser (Siemens, USA) using commercially available reagents.

Physicochemical properties of water

The physical and chemical properties of water are documented in Table 1. Water saturation with oxygen, $\mathrm{pH}$ and temperature were measured by the portable HACH HQ40D meter (Hach Lange, Germany). Conductivity measurements were taken by conductivity meter HI 98129 (Hanna Instruments, USA) and other chemical parameters were determined by standard methods (APHA 1998).

Statistical analyses

During the mathematical and statistical processing of the results, the selected biochemical indices were characterized by arithmetic mean values and standard deviation. The correlations between biochemical indices and basic water physicochemical characteristics such as temperature, $\mathrm{pH}$, etc. were analysed by Spearman's rank directional correlations. Values of $P=0.001$ were considered as significant. All the calculations were made using the statistical package Statistica 8.0 for Windows (StatSoft, USA).

\section{Results}

The blood plasma indices of fish are summarized in Table 2. Electrolytes, with the noticeable exception of potassium and iron, showed the lowest coefficients of variation whereas enzymes (namely creatine kinase, lipase, alanine aminotransferase and lactate dehydrogenase) showed the highest coefficient of variation.

Physicochemical properties of water affected a lot of indices in blood plasma of brook trout (Table 3). We found a significant influence of chemical properties of water on the content of alkaline phosphatase, cholinesterase, amylase, lipase, total protein, albumin, $\mathrm{P}, \mathrm{Ca}$ and $\mathrm{K}$ in plasma of brook trout. In contrast, physicochemical properties of the water did not influence values of acid phosphatase, aspartate aminotransferase, lactate dehydrogenase, glucose, urea and natrium in fish plasma. When monitoring the nitrite nitrogen, chlorides, sulphates, potassium and natrium, there was no conclusive influence of these chemical properties of water on blood plasma index by detected.

Statistical analysis showed a high correlation between plasma indices of fish and physicochemical properties of water. The most significant values $(P<0.001)$ are shown in Table 3.

\section{Discussion}

Changes of haematological and biochemical indices in brook trout could be caused by exhaustive exercise, stock density, health, nutrition, chemical or stress (Diouf et al. 2000; Congleton and Wagner 2006; Rehulka and Minař́ík 2007; Zusková et al. 2013).

Liver enzymes (ALT, AST and LDH) are the most frequently tested enzymes in fish used for the indication of toxicity, environmental pollution and nonspecific indicators of damage (Bucher 1990; Kopp et al. 2010). Our results have indicated none or minimal influence 


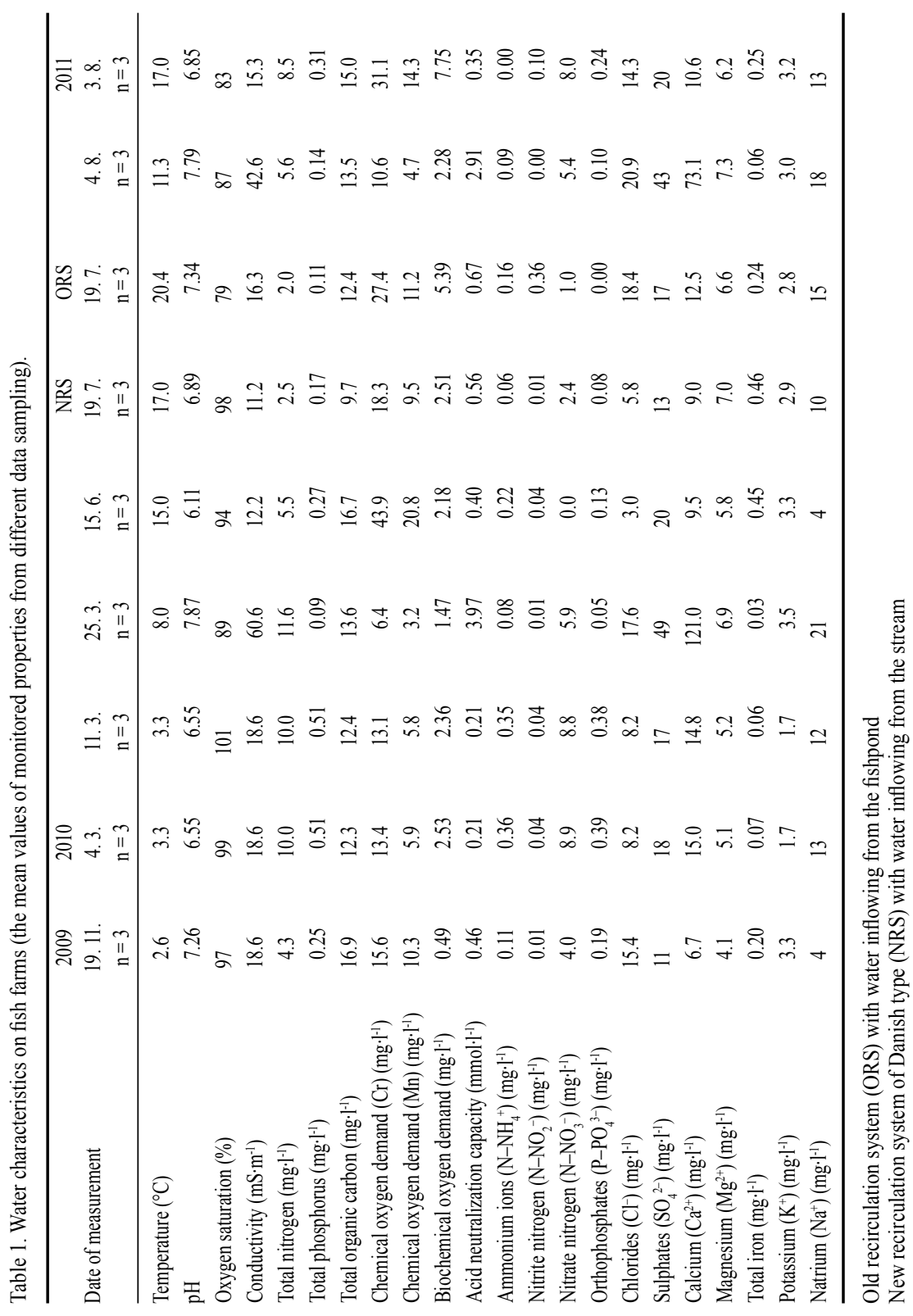

of physicochemical properties of water on values of activity of liver enzymes. Evidently, the monitored environmental factors have not negatively affected the function of fish liver and tissue damage.

The level of protein and lipid metabolism of salmonids corresponds to the contents of protein and lipid components in the diet (Congleton and Wagner 2006). The underlying factors on which is derived the function of lipid metabolism are lipase and triglycerides. 


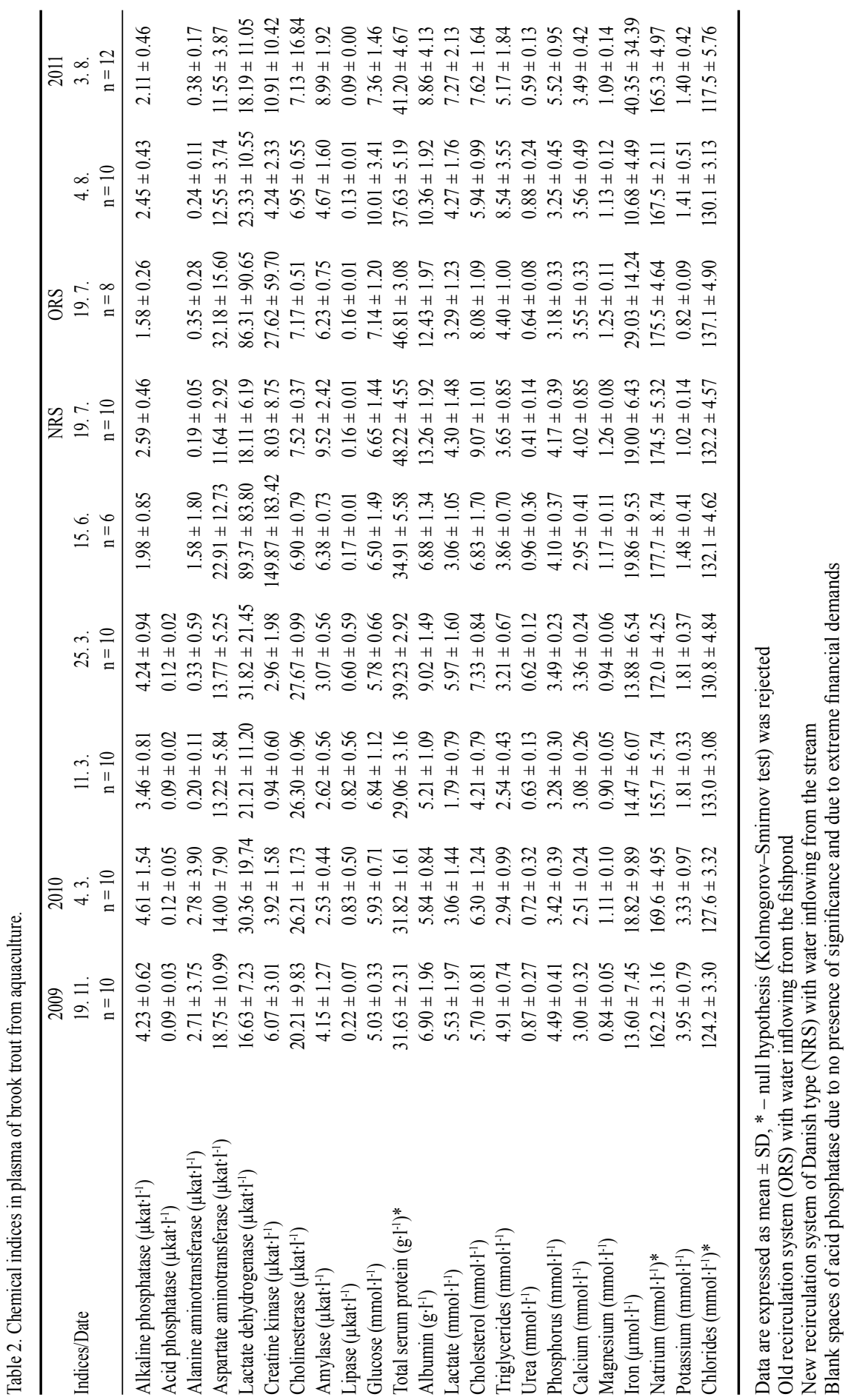




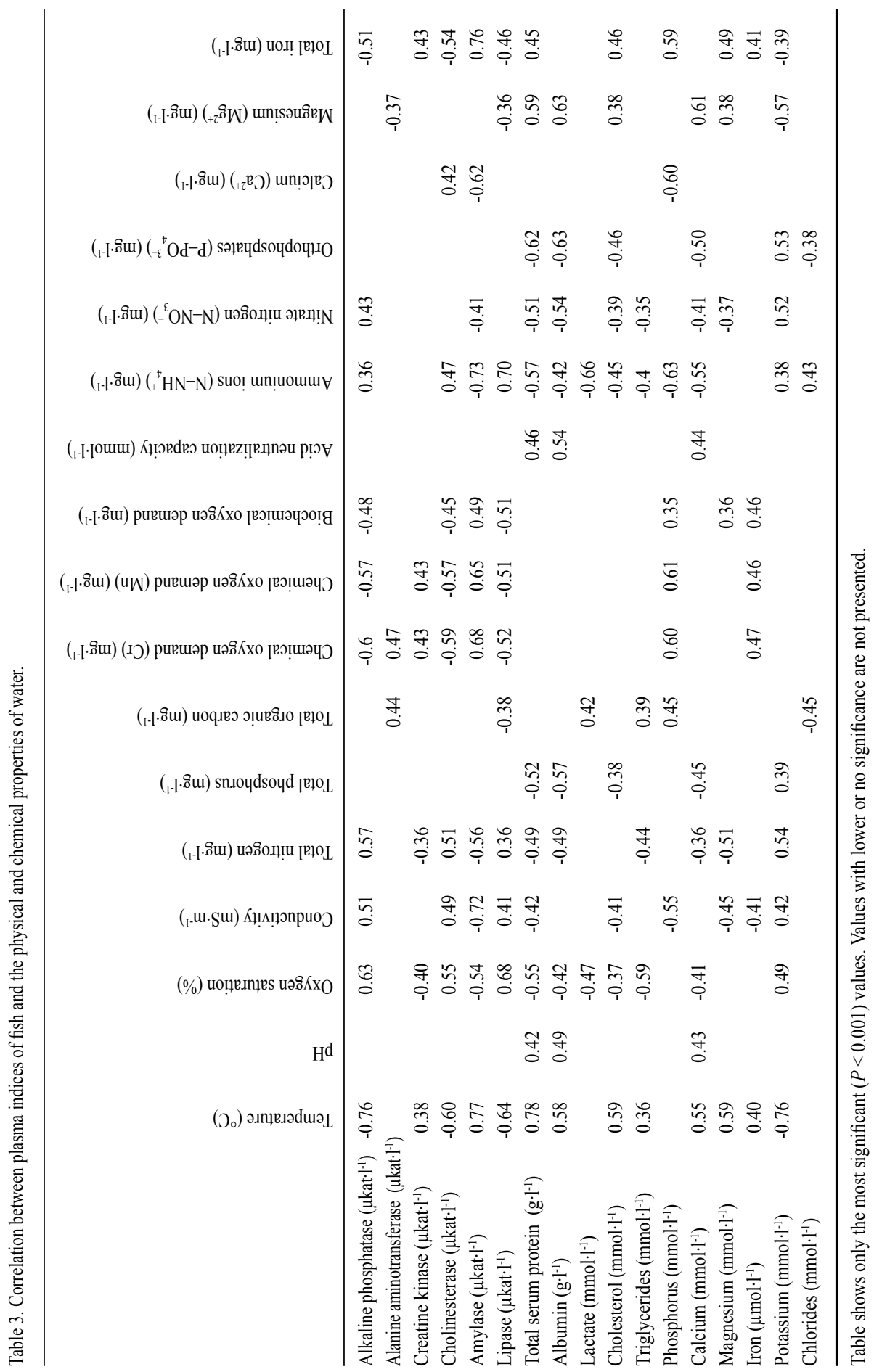


Plasma triglyceride concentrations may, however, be useful as one of a suite of bloodchemistry measurements if a multivariate approach is taken to assessment of nutritional condition (Wagner and Congleton 2004). Low concentration of plasma triglycerides has corresponded to depleted lipid reserves. These conclusions are supported by our results, when decrease of values of triglycerides came in the spring after the depletion of lipid reserves during the winter. The increased content of triglycerides was caused by increasing water temperature in our experiment, when feeding activity of fish grew up and plasma triglyceride concentrations were elevated after feeding, as lipids are absorbed from the gut and transported to the liver for further processing (Sheridan 1988).

The lipase activity in blood plasma of brook trout was affected mainly by differences in values of temperature, oxygen saturation, organic matter and ammonium ions of water. Increased values of plasma lipase in fish may be related to elevation of the liver lipase activity, which mediate the mobilization of liver lipid reserves in fish. Our monitoring confirms the results of other authors that values of plasma lipase activity are inverse to values of triglycerides, total phosphorus and cholesterol in blood plasma of fish (Congleton and Wagner 2006).

Total protein, cholesterol and alkaline phosphatase are responsive to changes in nutritional status (food intake, growth, body condition etc.). Storebakken et al. (1991) found that plasma protein concentrations were positively correlated with the feeding level in trout and declined during fasting. Several studies have likewise reported reduced plasma cholesterol concentrations and ALP activity in fasted or food deprivated salmonids (Bucher 1990). Our results positively showed the effect of water temperature on values of total protein and cholesterol in fish plasma and their inverse correlation with oxygen saturation of water and values of ammonium ions in fish. These variations of factors correspond with food intake intensity by fish and support the findings of other authors. The values of ALP inversely correlate with environmental factors as well as values of total protein and cholesterol. The specific metabolic role of ALP is unknown but it is believed to have function in the transport of ions and absorption of water across cell membranes. In the adult trout, plasma ALP activity declined after several weeks of food deprivation (Bucher 1990). The variation of ALP values in our experiment may be related to increased activity of liver caused by changes of environmental factors (e.g. ammonium ions), leading to increased transmembrane transport of ions and water, elevation of hepatic ALP activities and increased leakage of the enzyme into the blood plasma. The values of amylase in trout plasma significantly correlated with many environmental variables. Amylase is an enzyme responsible for metabolism of carbohydrates and their activity correlated with feeding level in fish. Our results showed the same trend of influence of physicochemical indices of water to amylase activity as with total protein and cholesterol.

Generally, food intake is the primary source of electrolytes to maintain the acid-base balance of trout. The importance of dietary ions intake is increasing at low $\mathrm{pH}$, when decreased intake of $\mathrm{Na}$ and $\mathrm{Cl}$ through gill epithelium (D'Cruz and Wood 1998). Trout, which lives in hypoosmotic environment, compensates for the absence of electrolytes by active intake through the gill epithelium associated with high water discharge by kidney (Evans et al. 2005). In our study, the values of individual electrolytes in blood plasma did not respond to their presence in the water except for iron and magnesium. The values of several electrolytes as magnesium, iron and phosphorus in blood plasma of fish are not related to nutritional condition or stress, but they are influenced by other factors such as water temperature or conductivity (Congleton and Wagner 2006). Contents of phosphorus in plasma were lower in the fish fed phosphorus-deficient diets than in those fed phosphorus-supplemented diets. Our results confirmed the findings of other authors about the influence of physicochemical indices of water on $\mathrm{Fe}, \mathrm{P}$ and $\mathrm{Mg}$ concentrations in blood plasma of fish. 
Calcium concentration is present in plasma in both ionized and bound forms. One half of total plasma calcium is ionized and one half is bound to plasma proteins (Andreasen 1985). Decline in plasma proteins in dependence on the decrease of food intake should also lower plasma calcium concentration, but plasma calcium decreases only after extended periods of deprivation of food (Congleton and Wagner 2006). Our results showed the same correlation trends about calcium and total plasma proteins in the blood plasma of brook trout. Evidently, the influence of physicochemical indices of water to calcium concentration in blood plasma related with food intake intensity.

There is no information in the literature about normal range of blood plasma chemistry in brook trout, likewise is reported by Manera and Britti (2006) with rainbow trout. Our results bring new information concerning variation of these indices in healthy fish reared under the conditions of intensive aquaculture. Based on our results it is clear that physical and chemical composition of water can have an influence on the changes of some indices of blood plasma and that impact can be more remarkable than previously thought. Our study suggests that the determination of blood plasma indices belongs to the rational indication of laboratory examination, if we want to evaluate and interpret the physiological response of the organism in an exhaustive manner.

\section{Acknowledgment}

This study was supported by the National Agency for Agricultural Research (grant No. QI91C001).

\section{References}

Andreasen P 1985: Free and total calcium concentrations in the blood of rainbow trout, Salmo gairdneri, during stress conditions. J Exp Biol 118: 111-120

APHA 1998: Standard methods for the examination of water and wastewater. American Public Health Association Inc., Washington D.C.

Bucher F 1990: Organ patterns and natural fluctuations of blood enzymes of rainbow trout (Salmo gairdneri Rich.). Comp Biochem Physiol B 96: 795-799

Congleton JL, Wagner T 2006: Blood-chemistry indicators of nutritional status in juvenile salmonids. J Fish Biol 69: 473-490

Diouf B, Rioux P, Blier UP, Rajotte D 2000: Use of brook char (Salvenilus fontinalis) physiological responses to stress as a teaching exercise. Adv Physiol Educ 23: 18-23

D'Cruz LM, Wood CM 1998: The influence of dietary salt and energy on the response to low pH in juvenile rainbow trout. Physiol Zool 71: 642-657

Evans D H, Piermarini P M, Choe K P 2005: The multifunctional fish gill: dominant site of gas exchange, osmoregulation, acid-base regulation, and excretion of nitrogenous waste. Physiol Rev 85: 97-177

Fulton T W 1904: The rate of growth of fishes. Fisheries Board of Scotland 22: 141-241

Kopp R, Palíková M, Navrátil S, Kubíček Z, Ziková A, Mareš J 2010: Modulation of biochemical and haematological indices of silver carp (Hypophthalmichthys molitrix Val.) exposed to toxic cyanobacterial water bloom. Acta Vet Brno 79: 135-146

Manera M, Britti D 2006: Assessment of blood chemistry normal range in rainbow trout. J Fish Biol 69: 14271434

Řehulka J, Minařík B 2008: Total calcium and inorganic phosphate in blood plasma in farmed rainbow trout, Oncorhynchus mykiss. Aquac Res 39: 1161-1168

Řehulka J, Minařík B 2007: Blood parameters in brook trout Salvenilus fontinalis (Mitchill, 1815), affected by columnaris disease. Aquac Res 38: 1182-1197

Sheridan MA 1988: Lipid dynamics in fish: aspects of absorbtion, transportion, deposition and mobilization. Comp Biochem Phys B 90: 679-690

Storebakken T, Hung SSO, Calvert CC, Plisetskaya EM 1991: Nutrient partitioning in rainbow trout at different feeding rates. Aquaculture 96: 91-203

Wagner T, Congleton JL 2004: Blood chemistry correlates of nutritional condition, tissue damage, and stress in migrating juvenile chinook salmon (Oncorhynchus tshawytscha) Can. J Fish Aquat Sci 61: 1066-1074

Zusková E, Máchová J, Velíšek J, Stará A, Svobodová Z, Kocour Kroupová H 2013: Recovery of rainbow trout (Oncorhynchus mykiss) after subchronic nitrite exposure. Acta Vet Brno 82: 73-79 